\title{
Changes in the Fluorescence Spectrum of Individual Single-Wall Carbon Nanotubes Induced by Light-Assisted Oxidation with Hydroperoxide
}

\author{
M. Zhang ${ }^{* 1}$, M. Yudasaka ${ }^{1,2}$, Y. Miyauchi ${ }^{3}$, S. Maruyama ${ }^{3}$, S. Iijima ${ }^{1,2,4}$ \\ ${ }^{1}$ SORST-JST, c/o NEC, 34 Miyukigaoka, Tsukuba, Ibaraki, 305-8501, Japan \\ ${ }^{2}$ NEC, 34 Miyukigaoka, Tsukuba, Ibaraki, 305-8501, Japan \\ ${ }^{3}$ Tokyo University, Bunkyo-ku, Tokyo 113-8656, Japan \\ ${ }^{4}$ Meijo University, Tempaku-ku, Nagoya 468-8502, Japan
}

\begin{abstract}
Through fluorescence-spectrum measurements, we investigated the effects of light-assisted oxidation with $\mathrm{H}_{2} \mathrm{O}_{2}$ (LAOx) on single-wall carbon nanotubes (SWNTs) that were individually dispersed in an aqueous solution of surfactant. The intensities of the fluorescence-spectra were decreased remarkably by the LAOx when the light's wavelength was $400-500 \mathrm{~nm}$, and a little when 600-700 nm. The spectrum intensity did not recover even when the $\mathrm{pH}$ was restored to an original value of 6.5. The spectra changed little when the LAOx wavelength was 500-600 nm, or the light was not irradiated. In addition, the effect of LAOx on SWNTs was related to the diameters of SWNTs. We inferred that these phenomena reflected that $\mathrm{H}_{2} \mathrm{O}_{2}$ was dissociated by absorbing the fluorescence light emitted from optically excited SWNTs, which, in turn, accelerated the burning out of SWNTs.
\end{abstract}




\section{Introduction}

Single-wall carbon nanotubes (SWNTs) [1] have attracted the attention of many researchers in various fields because of their interesting properties and potential applications [2]. The chemistry of SWNTs has been investigated with regard to purification [3-12], chemical functionalization [7, 10, 13-15], and the separation of tubes of different types (either metallic or semiconducting) [16-18]. In these processes, the oxidation of SWNTs plays important roles. The purification of as-grown SWNTs involves [3] combustion in $\mathrm{O}_{2}$ gas as well as treatment with strong acids such as $\mathrm{HNO}_{3}$ [5-6] and $\mathrm{H}_{2} \mathrm{SO}_{4} / \mathrm{HNO}_{3}$ [7]. Strong-acid treatments have also been used to open the tube ends and to cut long ropes of SWNTs into shorter lengths [7]. The combustion has also been used to narrow the diameter distribution of SWNTs [19-20] since SWNTs with smaller diameters combust more easily than those with larger diameters [21]. Recently, a method of light-assisted oxidation with $\mathrm{H}_{2} \mathrm{O}_{2}$ (LAOx) was proposed for selectively eliminating SWNTs with certain diameters [22]. However, it is not easy to understand the underlying phenomena of the LAOx, mainly because SWNTs aggregate and form bundles.

Technical advances in nanotube dispersion [23] now enable us to obtain individual SWNTs in an aqueous solution of surfactants such as sodium dodecyl sulfate (SDS), sodium dodecylbenzene sulfonate (NaDDBS) [24], or polymaleic acid/octyl vinyl ether (PMAOVE) [25]. Photoexcitation can cause individual semiconducting-SWNTs to exhibit fluorescence in near-IR regions, and from this fluorescence the electronic structures of semiconducting nanotubes have been elucidated [23, 26].

Through fluorescence-spectrum measurement, we studied the effects of LAOx on individual SWNTs dispersed in NaDDBS- $\mathrm{H}_{2} \mathrm{O}_{2}-\mathrm{H}_{2} \mathrm{O}$. Our results confirmed that visible-light irradiation accelerated the oxidation of SWNTs with $\mathrm{H}_{2} \mathrm{O}_{2}$, which is consistent with our previous results obtained using SWNT bundles [22]. We also found that the quenching of SWNT-fluorescence became irreversible as a result of LAOx, indicating that SWNTs were burnt-out. Moreover, we found that the effect of LAOx on SWNTs was related to both the wavelengths of light applied for the LAOx and the diameters SWNTs.

\section{Experimental Section}

The as-grown SWNTs used in this study were HiPco SWNTs [27] purchased from Carbon Nanotechnology Incorporated. To remove iron impurities from the SWNTs, we treated the as-grown SWNTs in oxygen at $300^{\circ} \mathrm{C}$ for 30 min to take the graphitic shell off the 
iron particles and then dispersed the SWNTs in $30 \% \mathrm{HCl}$ at $60^{\circ} \mathrm{C}$ for 5 hours followed by centrifuging. After decanting the supernatant, we washed the sediment with distilled water by using a centrifuge several times until the $\mathrm{pH}$ value was close to 7 . The final sediments of SWNTs were dried with a freezing-drier and further dried at $200^{\circ} \mathrm{C}$ under vacuum (50-100 Torr) for 1 hour to remove water molecules and electrolytes trapped inside the SWNTs [28]. The initial iron quantity contained in the SWNTs was about $40 \%$, which was reduced to about $5 \%$ after the purification. The iron quantity was estimated through thermogravimetric measurements.

The purified HiPco SWNTs were dispersed in $\mathrm{D}_{2} \mathrm{O}$ containing $0.5 \mathrm{wt} \%$ NaDDBS by using an ultrasonic processor equipped with a titanium alloy tip for $90 \mathrm{~min}$ at about $300 \mathrm{~W} / \mathrm{cm}^{2}$. The obtained dispersions were then centrifuged at 220,000 g for 2 to $3 \mathrm{~h}$, and about $70 \%$ of the supernatant volume was collected. It is believed that SWNTs prepared in this way mainly consist of isolated individual SWNTs [23, 24]. The fluorescence spectrum of SWNT-NaDDBS- $\mathrm{D}_{2} \mathrm{O}$ was measured in ranges of the excitation wavelength of $350-800 \mathrm{~nm}$ and a fluorescence wavelength of 800-1400 nm using a HORIBA SPEX Fluorelog-3-11 Spectrofluorometer, and the results were exhibited in a contour plot of fluorescence intensity versus excitation and emission wavelengths.

The LAOx, that is, light-assisted oxidation with $\mathrm{H}_{2} \mathrm{O}_{2}$, was performed as follows. The SWNT-NaDDBS- $\mathrm{D}_{2} \mathrm{O}$ was mixed with $30 \% \mathrm{H}_{2} \mathrm{O}_{2}$ aqueous solution. The volume ratio of the SWNTs-NaDDBS- $\mathrm{D}_{2} \mathrm{O}$ to the aqueous $\mathrm{H}_{2} \mathrm{O}_{2}$ solution was $1: 1$. This mixture is denoted as SWNTs-NaDDBS- $\mathrm{H}_{2} \mathrm{O}_{2}$ hereafter. The optical absorption spectrum of the $30 \% \mathrm{H}_{2} \mathrm{O}_{2}$ aqueous solution and SWNT-NaDDBS- $\mathrm{H}_{2} \mathrm{O}_{2}$ were measured with Lamda 19 UV/VIS/NIR spectrometer (Perkin-Elmer Corp.). Immediately after the mixing, the LAOx was started on SWNTs-NaDDBS- $\mathrm{H}_{2} \mathrm{O}_{2}$ at different wavelength-bands at room temperature for various periods. The wavelength bands were 400-500, 500-600, and 600-700 nm, which were obtained from a xenon lamp equipped with various optical band-pass filters. To eliminate infrared lights, a water filter that was set in front of the SWNTs-NaDDBS- $\mathrm{H}_{2} \mathrm{O}_{2}$ during the LAOx. The light powers of the three light-bands at the specimens were about $100 \mathrm{~mW} / \mathrm{cm}^{2}$.

Soon after LAOx ended, the fluorescence spectra of the SWNTs-NaDDBS- $\mathrm{H}_{2} \mathrm{O}_{2}$ and $\mathrm{pH}$ were measured. The excitation wavelength was 650 or $725 \mathrm{~nm}$, which corresponded to the second band gaps $\left(E_{22}\right)$ of SWNTs [29]. The fluorescence was detected in the range of 800 and $1500 \mathrm{~nm}$, which corresponded to the first band gap ( $\left.E_{11}\right)$ of semiconducting SWNTs [29]. 


\section{Results}

The fluorescence spectra of SWNTs-NaDDBS- $\mathrm{H}_{2} \mathrm{O}_{2}$ are shown in Fig. 1. Each peak corresponds to the emission from the first band gap $\left(E_{11}\right)$ of a semiconducting SWNT. It is clear that the spectrum remained almost unchanged when the SWNTs-NaDDBS- $\mathrm{H}_{2} \mathrm{O}_{2}$ was left without the light irradiation at room temperature for about 4 to 24 hours (Fig. 1a). However, when the LAOx's with various wavelengths for about 16 hours were performed on the SWNTs-NaDDBS- $\mathrm{H}_{2} \mathrm{O}_{2}$, their spectra changed. The LAOx with the light bandwidth of 400-500 nm (Fig. 1b) induced a large decrease in the intensity of SWNT emission peaks, while that with 500-600 nm (Fig. 1c) or 600-700 nm (Fig. 1d) caused smaller decreases.

Figure 2 shows that the $\mathrm{pH}$ values of the SWNTs-NaDDBS- $\mathrm{H}_{2} \mathrm{O}_{2}$ and $\mathrm{NaDDBS}-\mathrm{H}_{2} \mathrm{O}_{2}$ (without SWNTs) decreased as the LAOx period became longer. The greatest decrease in the $\mathrm{pH}$ of SWNTs-NaDDBS- $\mathrm{H}_{2} \mathrm{O}_{2}$ was observed when the LAOx wavelength was $400-500 \mathrm{~nm}$, followed in order by that $600-700 \mathrm{~nm}, 500-600 \mathrm{~nm}$, and without light-irradiation. Comparing the $\mathrm{pH}$ decrease of SWNTs-NaDDBS- $\mathrm{H}_{2} \mathrm{O}_{2}$ with that of $\mathrm{NaDDBS}-\mathrm{H}_{2} \mathrm{O}_{2}$ [30], the decrease of $\mathrm{pH}$ of SWNT-NaDDBS- $\mathrm{H}_{2} \mathrm{O}_{2}$ was greater, clearly showing the effect of the LAOx on SWNTs. After LAOx for 24 hours, we added several droplets of $\mathrm{Ba}(\mathrm{OH})_{2}$ aqueous solution to the SWNTs-NaDDBS- $\mathrm{H}_{2} \mathrm{O}_{2}$ and NaDDBS- $\mathrm{H}_{2} \mathrm{O}_{2}$. We noticed that the transparent-solution changed to a white cloudy-suspension (not shown), which might have been due to particle generation of water-insoluble $\mathrm{BaCO}_{3}$ and/or $\mathrm{BaSO}_{4}$. This indicates that SWNTs and NaDDBS were degraded by $\mathrm{H}_{2} \mathrm{O}_{2}$ and generated $\mathrm{CO}_{2}, \mathrm{CO}_{3}{ }^{2-}$, and $\mathrm{SO}_{4}{ }^{2-}$.

Since it is reported that the $\mathrm{pH}$ of an SWNT solution affects the fluorescence spectra of SWNTs [23, 31], we also investigated this influence. We changed the $\mathrm{pH}$ of SWNTs-NaDDBS- $\mathrm{H}_{2} \mathrm{O}_{2}$ (24 hours, no light-irradiation) with $0.2 \mathrm{~N} \mathrm{HCl}$ and $0.2 \mathrm{~N} \mathrm{NaOH}$ in the order of $6.5 \rightarrow 4 \rightarrow 2 \rightarrow 6.5$, and measured the fluorescence spectra at each $\mathrm{pH}$. We found that the peak intensities decreased as the $\mathrm{pH}$ fell, and then recovered when the $\mathrm{pH}$ returned to 6.5 when no light was irradiated (Fig. 3a). However, the spectrum peaks that decreased after LAOx did not recover even when the $\mathrm{pH}$ was restored to 6.5. For example, after LAOx at 400-500 nm for 24 hours (Fig. 3b), the fluorescence intensities of the SWNTs-NaDDBS- $\mathrm{H}_{2} \mathrm{O}_{2}$ greatly decreased (red lines) accompanying the $\mathrm{pH}$ decrease from about 6.5 to 2.0. The decreased fluorescence intensities did not recover even when the $\mathrm{pH}$ was restored to 6.5 (blue lines).

Adjusting the $\mathrm{pH}$ values to 6.5, the changes of fluorescence spectra of SWNTs-NaDDBS- $\mathrm{H}_{2} \mathrm{O}_{2}$ caused by the LAOx at 400-500, 500-600, and 600-700 nm for 
various periods appeared as shown in Fig. 4. These fluorescence spectra in Fig. 4 were not different very much from those measured without adjusting the $\mathrm{pH}$ values at 6.5 (Fig. 1). The degree of spectral quenching by the LAOx followed the order $400-500 \mathrm{~nm}$ >> 600-700 $\mathrm{nm}>>$ 500-600 nm > no irradiation of light.

To clarify the influence of LAOx at 400-500 and 600-700 nm on SWNTs, we analyzed the $\mathrm{pH}$-corrected fluorescence-spectra of SWNTs-NaDDBS- $\mathrm{H}_{2} \mathrm{O}_{2}$ in Figs. $4 \mathrm{~b}$ and $4 \mathrm{~d}$ by Lorentzian deconvolution. The spectra in Figs. 4b and 4d were deconvoluted into 12 peaks (P1 to P12). The chiral indexes of SWNTs corresponding to P1 to P12 were assigned according to the empirical Kataura plots [32]. In Table 1, chiral indexes are listed in the order of the fluorescence quenching coefficient. The quenching coefficient is defined as $-\left(\mathrm{I}-\mathrm{I}_{0}\right) / \mathrm{I}_{0}$ where, "I" and " $\mathrm{I}_{0}$ " refer to the emission-peak heights of the SWNTs-NaDDBS- $\mathrm{H}_{2} \mathrm{O}_{2}$ before and after LAOx, respectively. The quenching coefficients, $-\left(\mathrm{I}-\mathrm{I}_{0}\right) / \mathrm{I}_{0}$, for P1 to P12 are plotted against the SWNT diameters in Fig. 5 for various periods of LAOx. The graphs in Fig. 5 for 400-500 nm irradiation (top) and 600-700 nm irradiation (bottom) show that the fluorescence quenching was largest for small-diameter $(<0.9 \mathrm{~nm})$ SWNTs. It is curious that the quenching for large diameter $(>0.97 \mathrm{~nm})$ SWNTs exceeded that for SWNTs with moderate diameters $(0.9-0.97 \mathrm{~nm})$.

\section{Discussion}

Our results indicated that light irradiation of the SWNTs-NaDDBS- $\mathrm{H}_{2} \mathrm{O}_{2}$ enhanced the decrease in the solution's pH (Fig. 2) and the fluorescence quenching of SWNTs (Fig. 1). The decreased intensities did not recover even after the $\mathrm{pH}$ values were restored to the initial $\mathrm{pH}$ of 6.5 (Figs. 3 and 4). This differed from the findings of Dukovic et al. [25], Strano et al. [31], and Zhao et al [33]. These three studies indicate that the optical-absorption bleaching and luminescence quenching are caused by the formation of nanotube oxides or functional groups on the SWNT surface at low $\mathrm{pH}$, and this can be completely reversed by adjusting the $\mathrm{pH}$. We believe that the irreversibility of the fluorescence spectra in our experiments indicates that the SWNTs were burnt out as a result of LAOx.

\section{The influence of light wavelength}

Since the aqueous solution of $\mathrm{H}_{2} \mathrm{O}_{2}$ or NaDDBS- $\mathrm{H}_{2} \mathrm{O}_{2}$ did not absorb 400-700 nm light (Fig. 6a), their photo-degradation by $400-700 \mathrm{~nm}$ irradiation was unlikely to happen, and thus could not cause the wavelength dependence of the LAOx efficiency as shown in Fig. 4. In 
addition, our experiments revealed little difference in the absorbance of SWNT-NaDDBS- $\mathrm{H}_{2} \mathrm{O}_{2}$ in the regions of 400-500, 500-600, and 600-700 nm (Fig. 6b). It is also unlikely that SWNT light-absorption caused the wavelength dependence of the LAOx efficiency seen in Fig. 4.

A more reasonable explanation for the wavelength dependence of the LAOx (Fig. 4) is as follows. Since $\mathrm{H}_{2} \mathrm{O}_{2}$ absorbs the light with wavelength of $>1300 \mathrm{~nm}$ [34], it would absorb the SWNT fluorescence with wavelength $>1300 \mathrm{~nm}$. This would enhance the dissociation of $\mathrm{H}_{2} \mathrm{O}_{2}$ and the generation of hydroxyl radicals [35], which, in turn, would burn out SWNTs. In Fig. 7, we show a Kataura plot [36] for the diameter range of 0.7 to $1.3 \mathrm{~nm}$. (In the plot, the color squares indicate the light bands used in LAOx.) The SWNTs in black boxes in Fig.7 had the gap energies corresponding to the LAOx wavelength of $400-500 \mathrm{~nm}(2.48-3.1 \mathrm{eV})$ or $600-700 \mathrm{~nm}(1.77-2.07 \mathrm{eV})$ and the emission wavelengths at $>1300 \mathrm{~nm}(<0.95 \mathrm{eV})$. Apparently, the number of SWNT types in the black box corresponding to the $400-500 \mathrm{~nm}$ exceeded that corresponding to the $600-700 \mathrm{~nm}$. The light wavelength band of 500-600 nm did not correspond to any SWNTs that emitted light with wavelength $>1300 \mathrm{~nm}$. This was well reflected in the fluorescence spectra shown as a function of excitation wavelength for SWNTs-NaDDBS- $\mathrm{H}_{2} \mathrm{O}$ (Fig. 7b). We believe that the absorption of the SWNT-fluorescence by $\mathrm{H}_{2} \mathrm{O}_{2}$ was the main factor that caused the photo-dissociation of $\mathrm{H}_{2} \mathrm{O}_{2}$, leading to the generation of the hydroxyl radicals [35]. This accelerated the oxidation of SWNTs. Thus we consider that the number of SWNT types in the black boxes in Fig.7 could induce the wavelength dependence of the LAOx, 400-500 >> 600-700 >> 500-600 nm (Fig. 4).

Raman spectra and absorption spectra would be helpful for determining the structure of the SWNTs removed by the LAOx, but they could not be properly measured in this study. The charge transfer between SWNTs and $\mathrm{H}_{2} \mathrm{O}_{2}$ influenced the Raman spectra of the SWNTs and the absorption measurement baseline changed with the duration of the LAOx due to the variation of the contents of $\mathrm{H}_{2} \mathrm{O}_{2}$ and NaDDBS in the SWNTs-NaDDBS- $\mathrm{H}_{2} \mathrm{O}_{2}$.

\section{Elimination of SWNTs with diameter selectivity}

Our results also indicated that the change in the quenching coefficients was related to the SWNT diameters (Fig. 5). The quenching coefficients of the small-diameter SWNTs were more negative than those of the large-diameter SWNTs. This means that the small-diameter SWNTs were burnt out more easily than the large-diameter ones, which is consistent with the previous reports [19-21]. Figure 5 also suggested that the SWNTs with larger diameters ( $>0.97 \mathrm{~nm})$ burnt out more remarkably than those with moderate diameters $(0.9-0.97 \mathrm{~nm})$. 
We tentatively think that $\mathrm{H}_{2} \mathrm{O}_{2}$ entered inisde the SWNTs when their diameters were large $(>0.97 \mathrm{~nm})$, and the photo-dissociation proceeded more efficiently through the absorption of SWNT-fluorescence because of the short distance between the SWNT wall and $\mathrm{H}_{2} \mathrm{O}_{2}$. Thus the SWNT burning by the LAOx became more efficient when the SWNT diameter was large [37, 38-39].

\section{Conclusion}

We have investigated the changes in the fluorescence spectra of individual SWNTs induced by LAOx, that is, light-assisted oxidation with $\mathrm{H}_{2} \mathrm{O}_{2}$. We could confirm our previous result that the light irradiation can accelerate the oxidation of SWNTs with $\mathrm{H}_{2} \mathrm{O}_{2}$ [22]. Since the fluorescence spectra of SWNTs quenched by LAOx could not be restored by $\mathrm{pH}$ adjustment, we believe that SWNTs were burnt out by the LAOx. The LAOx efficiency depended on the irradiating light-wavelength in the order of 400-500 >> 600-700 >> 500-600 $\mathrm{nm}>$ no light. We believe that the absorption of the SWNT-fluorescence by $\mathrm{H}_{2} \mathrm{O}_{2}$ was the main factor that caused the photo-dissociation of $\mathrm{H}_{2} \mathrm{O}_{2}$ and the generation of the hydroxyl radicals [35]. This accelerated the oxidation of SWNTs. The dependence of LAOx on the wavelength was explained with the number of SWNT types that emit the flueorescence with wavelength $>1300 \mathrm{~nm}$ by which $\mathrm{H}_{2} \mathrm{O}_{2}$ was likely to be photo-dissociated.

The effect of LAOx depended on the SWNT diameters. It was interesting that the SWNTs with larger diameters $(>0.97 \mathrm{~nm})$ were burnt out more remarkably than those with moderate diameters (0.9-0.97 nm). This would reflect that $\mathrm{H}_{2} \mathrm{O}_{2}$ entered inside the SWNTs, and enhanced the SWNT burning by the LAOx through the photo-dissociation of $\mathrm{H}_{2} \mathrm{O}_{2}$ caused by absorbing the SWNT-fluorescence efficiently due to the short distance between the SWNT walls and $\mathrm{H}_{2} \mathrm{O}_{2}$. 


\section{Figure captions}

Fig.1 Fluorescence spectra (excitation wavelength: 650 and $725 \mathrm{~nm}$ ) of SWNTs-NaDDBS- $\mathrm{H}_{2} \mathrm{O}_{2}$ left for various periods in darkness (a), and with light irradiation (LAOx) at wavelength bands of 400-500 (b), 500-600 (c), and 600-700 nm (d). For easy comparison, the black line of Fig. 1a is added in Figs. 1b, 1c, and 1d.

Fig. 2 Changes in the $\mathrm{pH}$ values of SWNTs-NaDDBS- $\mathrm{H}_{2} \mathrm{O}_{2}$ (solid lines) and $\mathrm{NaDDBS}-\mathrm{H}_{2} \mathrm{O}_{2}$ solutions (broken lines) with an increase of periods left in darkness or LAOx at various wavelength bands of 400-500, 500-600, and 600-700 nm.

Fig. 3 (a) Fluorescence spectra (excitation wavelength: 650, $725 \mathrm{~nm}$ ) of SWNT-NaDDBS- $\mathrm{H}_{2} \mathrm{O}_{2}$ after being left in darkness for $24 \mathrm{~h}$; $\mathrm{pH} 6.5$ (black curve) and that after the $\mathrm{pH}$ was adjusted to 2.0, 4.0, and 6.5. (b) Fluorescence spectra of SWNT-NaDDBS- $\mathrm{H}_{2} \mathrm{O}_{2}$ after LAOx at 400-500 nm for $24 \mathrm{~h}$; $\mathrm{pH} 2.0$ (red curve) and that after the $\mathrm{pH}$ was adjusted to 6.5 (blue curve).

Fig. 4 Fluorescence spectra (excitation wavelength: 650, $725 \mathrm{~nm}$ ) of the SWNTs-NaDDBS- $\mathrm{H}_{2} \mathrm{O}_{2}$ after being left in darkness (a), and those after LAOx for 4 to 24 hours at 400-500 nm (b), 500-600 nm (c), and 600-700 nm (d). The fluorescence spectra were measured after the $\mathrm{pH}$ was adjusted to 6.5.

Fig. 5 Quenching coefficients, $-\left(\mathrm{I}-\mathrm{I}_{0}\right) / \mathrm{I}_{0}$, for various periods of LAOx are indicated as a function of the SWNT diameters. Here, "I" and "I $\mathrm{I}_{0}$ ” refer to the fluorescence-peak heights of the SWNTs-NaDDBS- $\mathrm{H}_{2} \mathrm{O}_{2}$ after LAOx and being left in dark, respectively. These values were calculated from the Lorentzian deconvolution of the fluorescence spectra for SWNTs-NaDDBS- $\mathrm{H}_{2} \mathrm{O}_{2}$ left in darkness and after LAOx at 400-500 and 600-700 nm for various lengths of time (Fig. $4 \mathrm{~b}$ and Fig. $4 \mathrm{~d}$ ).

Fig. 6 Absorption spectra of $30 \%$ aqueous solution of $\mathrm{H}_{2} \mathrm{O}_{2}$ (a), $\mathrm{NaDDBS}-\mathrm{H}_{2} \mathrm{O}_{2}$ (a), and SWNTs-NaDDBS- $\mathrm{H}_{2} \mathrm{O}_{2}$ (b).

Fig. 7 (a) Kataura plot. The light wavelength bands of 400-500 nm, 500-600 nm, and 600-700 
$\mathrm{nm}$ are shown as color squares. The inserted black boxes indicate SWNTs whose gap energies corresponded to the light wavelength bands of 400-500 nm (2.48-3.1 eV) and 600-700 nm (1.77-2.07 eV) and had emission wavelengths of $>1300 \mathrm{~nm}(<0.95 \mathrm{eV})$. (b) A contour plot of fluorescence intensity versus excitation and emission wavelengths for SWNTs-NaDDBS- $\mathrm{D}_{2} \mathrm{O}$. The $(m, n)$ inserted in Fig. 7b was the chiral index of the SWNT assigned using the empirical Kataura plot [32]. 


\section{Notes and References}

[1] Iijima, S.; Ichihashi, T. Nature 1993, 363, 603.

[2] Carbon Nanotubes: Synthesis, Structure, Properties, and Application, Dresselhaus, M. S.; Dresselhaus, G.; Avouris, P. H. (eds.), Springer, New York, 2001.

[3] Tohji, J.; Goto, T.; Takahashi, H.; Shinoda, Y.; Shimizu, N.; Jeyadevan, B.; Matsuoka, I.; Saito, Y.; Kasuya, A.; Ohsuna, T.; Hiraga, K.; Nishina, Y. Nature 1996, 383, 679.

[4] Bandow, S.; Asaka, S.; Zhao, X.; Ando, Y. Appl. Phys. A 1998, 67, 23.

[5] Rinzler, A. G.; Liu, J.; Dai, H.; Nikolaev, P.; Huffman, C. B.; Rodriguez-Macias, F. J.; Boul, P. J.; Lu, A. H.; Heymann, D.; Colbert, D. T.; Lee, R. S.; Fischer, J. E.; Rao, A. M.; Eklund, P. C.; Smalley, R. E. Appl. Phys. A 1998, 67, 29.

[6] Dillon, A. C.; Gennett, T.; Jones, K. M.; Alleman, J. L.; Parilla, P.; Heben, M. J. Adv. Mater. 1999, 11, 1354. $\left(\mathrm{HNO}_{3}\right)$

[7] Liu, J.; Rinzler, A. G.; Dai, H.; Hafner, J. H.; Bradley, R. K.; Boul, P. J.; Lu., A.; Iverson, T.; Shelimov, K.; Huffman, C. B.; Rodriguez-Macias, F.; Shon, Y.; Lee, T. R. Science, 1998, 280, 1253-1256. (cut, $\mathrm{HNO}_{3}-\mathrm{H}_{2} \mathrm{SO}_{4}$ )

[8] Chiang, I. W.; Brinson, B. E.; Smalley, R. E.; Margrave, J. L.; Hauge, R. H. J. Phys. Chem. B 2001, 105, 1157. $\left(\mathrm{O}_{2}, \mathrm{HCl}\right)$

[9] Yudasaka, M.; Zhang, M.; Jabs, C.; Iijima, S. Appl. Phys. A 2000, 71, 1.

[10] Hu, H.; Zhao, B.; Itkis, M. E.; Haddon, R. C. J. Phys. Chem. B 2003, 107, 13838. (nitric acid, damage)

[11] Yang, C. M.; Kaneko, K.; Yudasaka, M.; Iijima, S. Nano Lett. 2002, 2, 385. (HiPco, $\mathrm{HCl}$ ).

[12] Xu. Y.; Peng, H.; Hauge, R. H.; Smalley, R. E. Nano Lett. 2005, 5, 163. (HiPco SF4, $\mathrm{HCl}$.$) .$

[13] Koshio, A.; Yudasaka, M.; Zhang, M.; Iijima, S. Nano Lett. 2001, 1, 361. (sonication)

[14] Khabashesku, V. N.; Billups, W. E.; Margrave, J. L. Acc. Chem. Res. 2002, 35, 1087. (F)

[15] Stevens, J. L.; Huang, A. Y.; Peng, H.; Chiang, I. W.; Khabashesku, V. N.; Margrave, J. L. Nano Lett. 2003, 3, 331. (Amino-)

[16] Krupke, R.; Hennrich, F.; Lohneysen, H. V.; Kappes, M. Science 2003, 301, 344. (separation)

[17] Zheng, M.; Jagota, A.; Strano, M. S.; Santos, A. P.; Barone, P.; Chou, S. G.; Diner, B. A.; Dresselhaus, M. S.; Mclean R. S.; Onoa, G. B.; Samsonidze, G. G.; Semke, E. D.; Usrey, M.; Walls, D. J. Science 2003, 302, 1548. (DNA) 
[18] Chen, Z.; Du, X.; Du, M.; Rancken, C. D.; Cheng, H.; Rinzler, A. G. Nano Lett. 2003, 3, 1245. (separation)

[19] Zhou, W., Ooi, Y. H., Russo, R., Panek, P., Luzzi, D. E., Fischer, J. E., Bronikowski, M. J., Willis, P. A., Smalley, R. E. Chem. Phys.Lett. 2001, 350, 6.

[20] Zhang, M.; Yudasaka, M.; Iijima, S. J. Phys. Chem. B, 2005, 109, 6037.

[21] Nagasawa, S.; Yudasaka, M.; Hirahara, K.; Ichihashi, T.; Iijima, S. Chem. Phys. Lett. 2000, 328, 374

[22] Yudasaka, M.; Zhang, M.; Iijima, S., Chem. Phys. Lett. 2003, 374, 132.

[23] O’Connell, M. J.; Bachilo, S. M.; Huffman, C. B.; Moore, V. C.; Strano, M. S.; Haroz, E. H.; Rialon, K. L.; Boul, P. J.; Noon, W. H.; Kittrell, C.; Ma, J.; Hauge, R. H.; Weisman, R. B.; Smalley, R. E. Science 2002, 297, 593.

[24] Matarredona, O.; Rhoads, H.; Li, Z.; Harwell, J. H.; Balzano, L.; Resasco, D. E. J. Phys. Chem. B 2003, 107, 13357

[25] Dukovic, G.; White, B. E.; Zhou, Z.; Wang, F.; Jockusch, S.; Steigerwald, M.; Heinz, T. F.; Friesner, R. A.; Turro, N. J.; Brus, L. E. J. Am. Chem. Soc. 2004, 126, 15269.

[26] Bachilo, S. M.; Strano, M. S.; Kittrell, C.; Hauge, R. H.; Smalley, R. E.; Weisman, R. B.; Science, 2002, 298, 2361.

[27] Nikolaev, P.; Bronikowski, M. J.; Bradley, R. K.; Rohmund, F.; Colbert, D. T.; Smith, K. A.; Smalley, R. E. Chem.. Phys. Lett. 1999, 313, 91.

[28] Zhang, M.; Yudasaka, M.; Iijima, S. J. Phys. Chem. B 2005, 109, 6037.

[29] Saito, R.; Dresselhaus, G.; Dresselhaus, M. S Phys. Rev. B 2000, 61, 1981.

[30] Because the aqueous solution of $\mathrm{NaDDBS}-\mathrm{H}_{2} \mathrm{O}_{2}$ does not absorb the light in 400-700 nm (Fig. 6a), it is unusual that the light irradiation enhanced the oxidation or decomposition of NaDDBS- $\mathrm{H}_{2} \mathrm{O}_{2}$. We tentatively think when $\mathrm{NaDDBS}$ was oxidized by $\mathrm{H}_{2} \mathrm{O}_{2}$, it might form the intermediate oxides which absorbed the visible light and then accelerated the further decomposition of NaDDBS, leading to the $\mathrm{pH}$ value of solution to decrease.

[31] Strano, M. S.; Huffman, C. B.; Moore, V. C.; O’Connell, M. J.; Haroz, E. H.; Hubbard, J.; Miller, M.; Rialon, K.; Kittrell, C.; Ramesh, S.; Hauge, R. H.; Smalley, R. E. J. Phys. Chem. B 2003, 107, 6979.

[32] Weisman, R. S.; Bachilo, S. M. Nano Lett. 2003, 3, 1235. (E-plot)

[33] Zhao, W.; Song, C.; Pehrsson, P. E. J. Am. Chem. Soc. 2002, 124, 12418.

[34] Pimenta et al. J. Near Infrared Spectroscop. 2003

[35] Hydrogen peroxide, http://www. $\mathrm{H}_{2} \mathrm{O}_{2} \cdot \mathrm{com} /$

[36] Kataura, H.; Kumazama, Y.; Maniwa, Y.; Umezu, I.; Suzuki, S.; Ohtsuka, Y.; Achiba, Y. 
Synth. Met. 1999, 103, 2555.

[37] It is known that charge transfer occurrs between SWNT and $\mathrm{H}_{2} \mathrm{O}_{2}[38,39]$. The effect of energy state change caused by the charge transfer was not explicitly observed in our results.

[38] Strano, M. S. J. Am. Chem. Soc. 2003, 125, 16148.

[39] Okazaki, K.; Nakato, Y.; Murakoshi, K. Phys. Rev. B 2003, 68, 035434. 
M. Zhang et al. Fig. 1
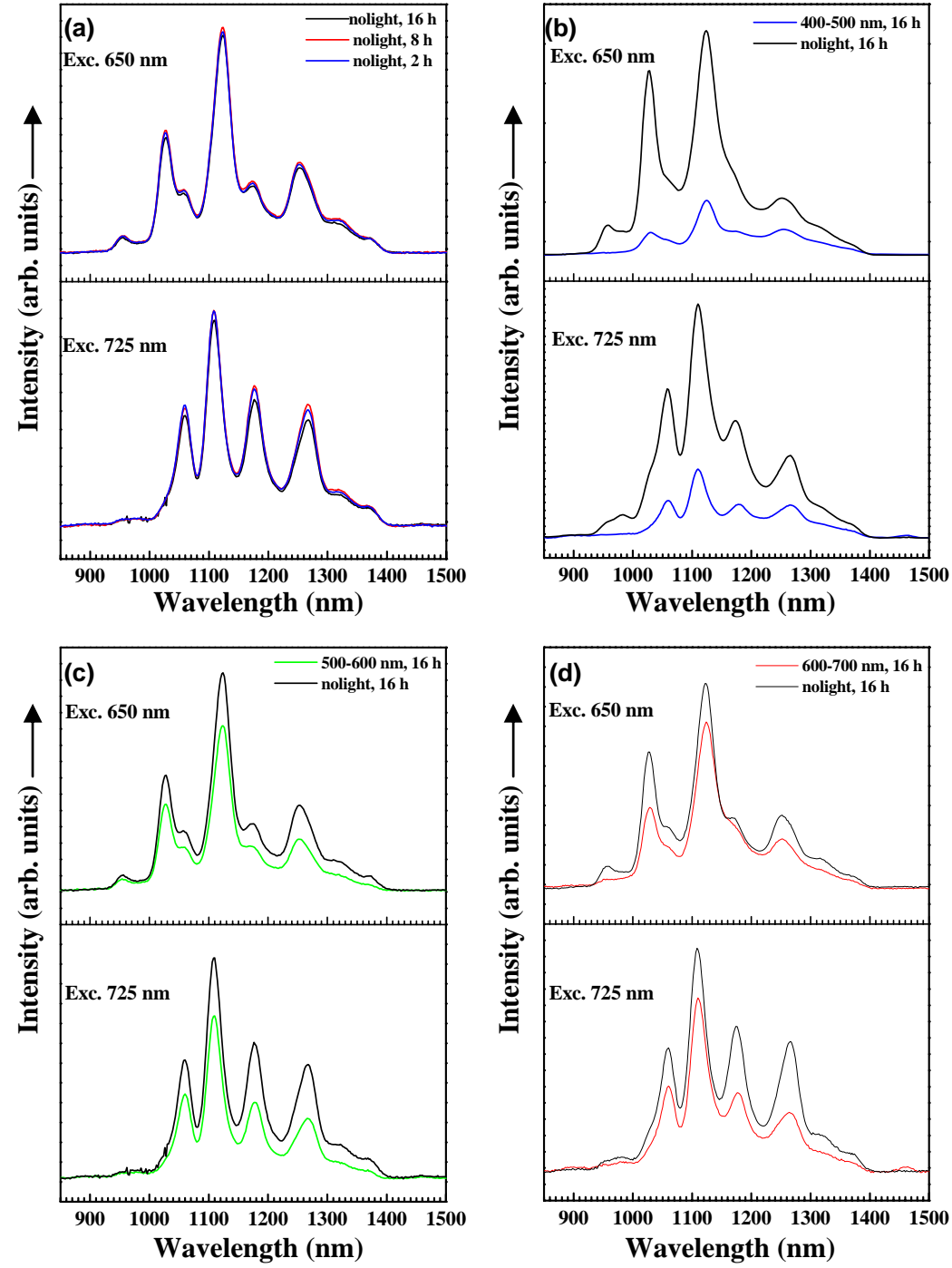
M. Zhang et al. Fig. 2

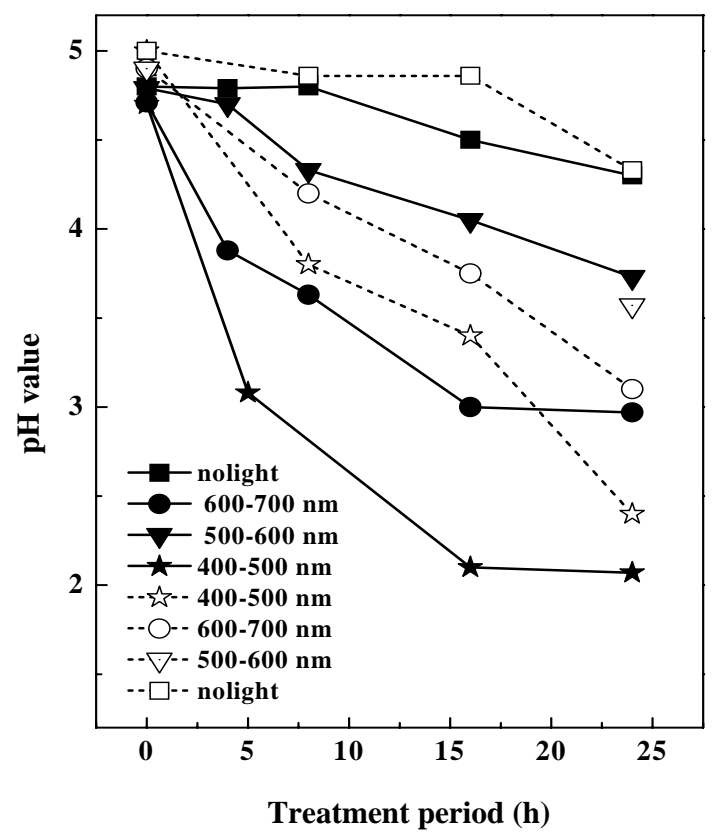


M. Zhang et al. Fig. 3
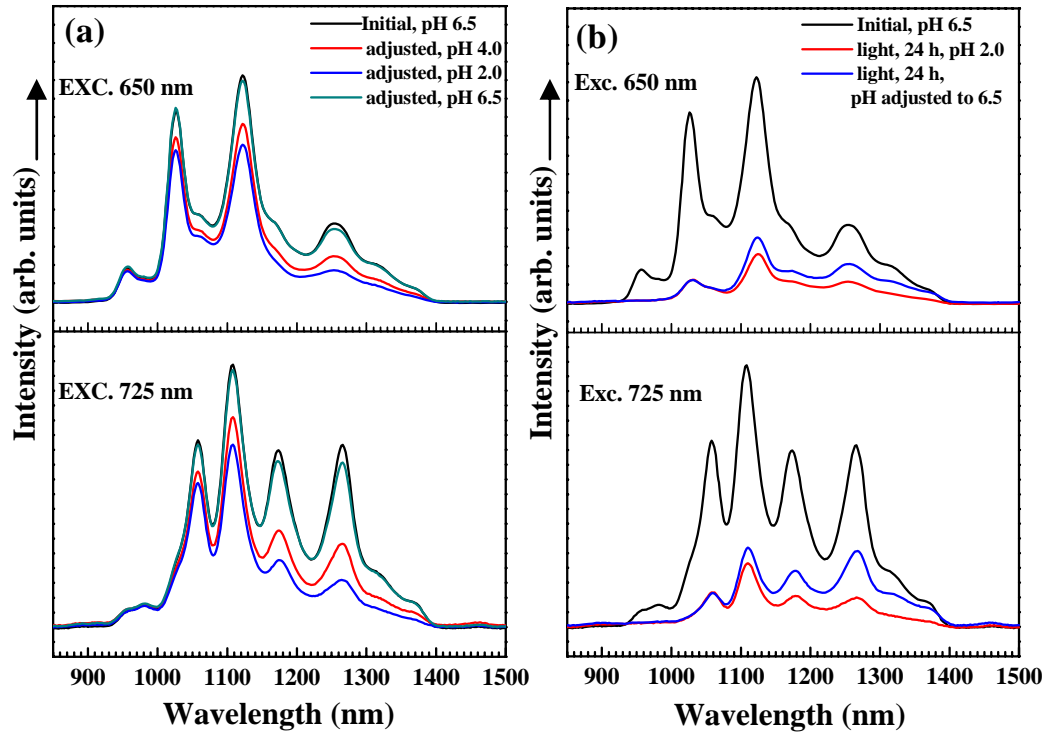
M. Zhang et al. Fig. 4

(a) Without light irradiation

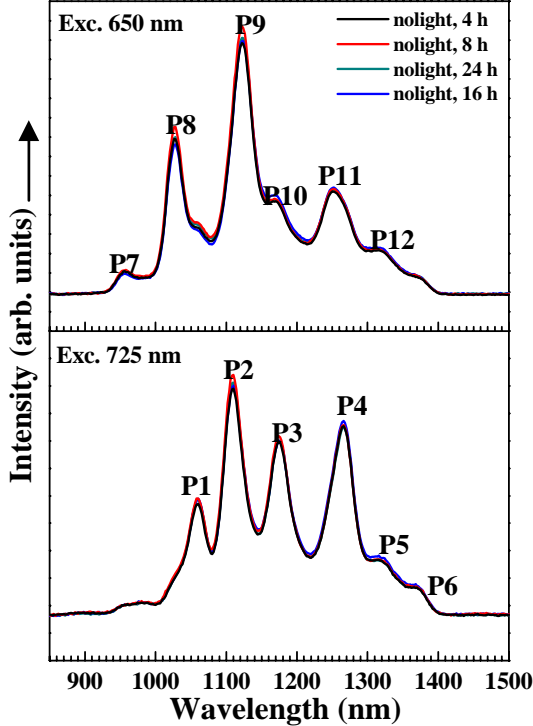

(c) Light: $500-600 \mathrm{~nm}$

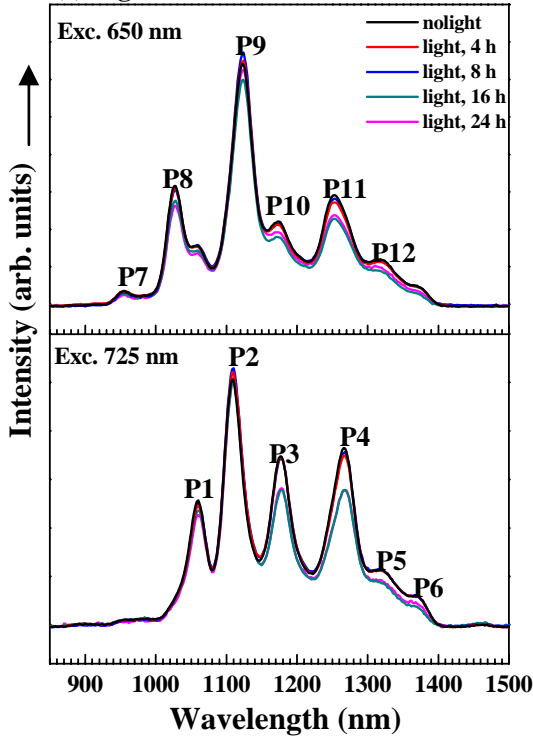

(b) Light: 400-500 nm

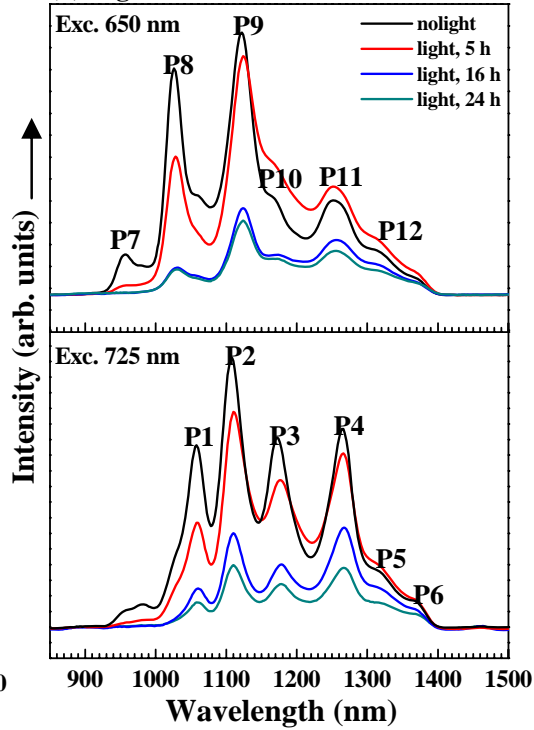

(d) Light: 600-700 nm

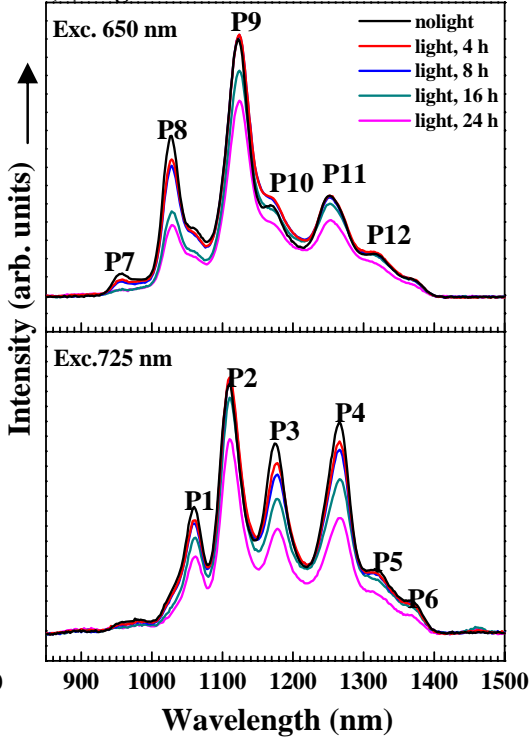


M. Zhang et al. Fig. 5

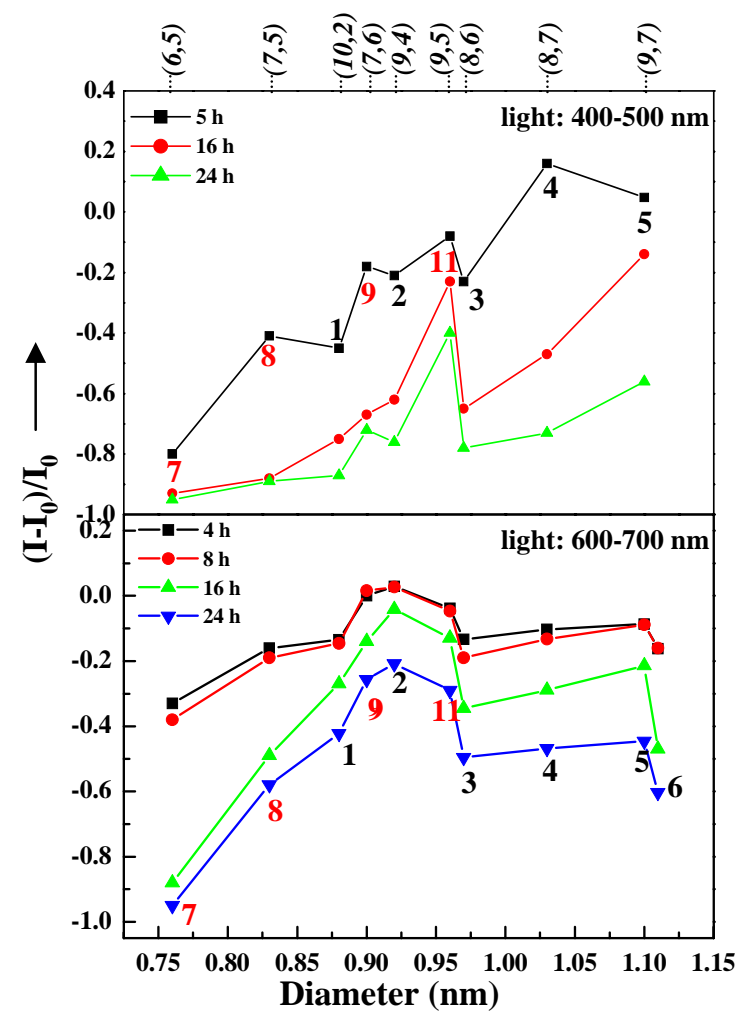


M. Zhang et al. Fig. 6
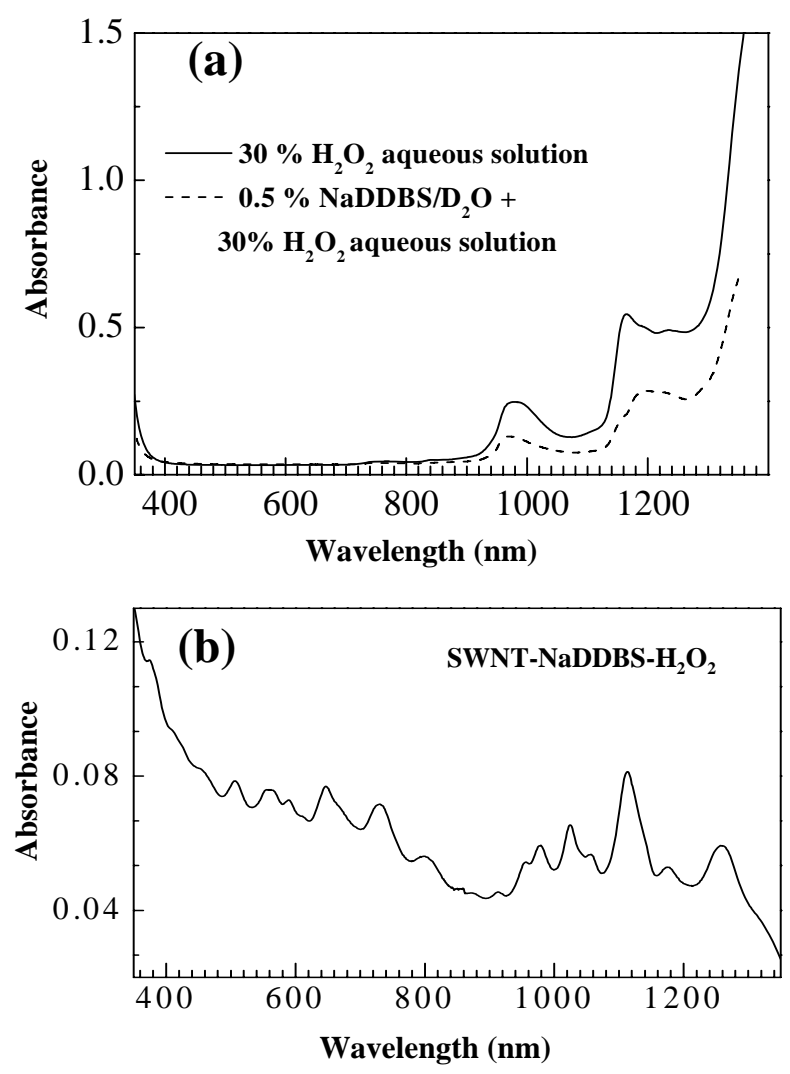
Fig. 7
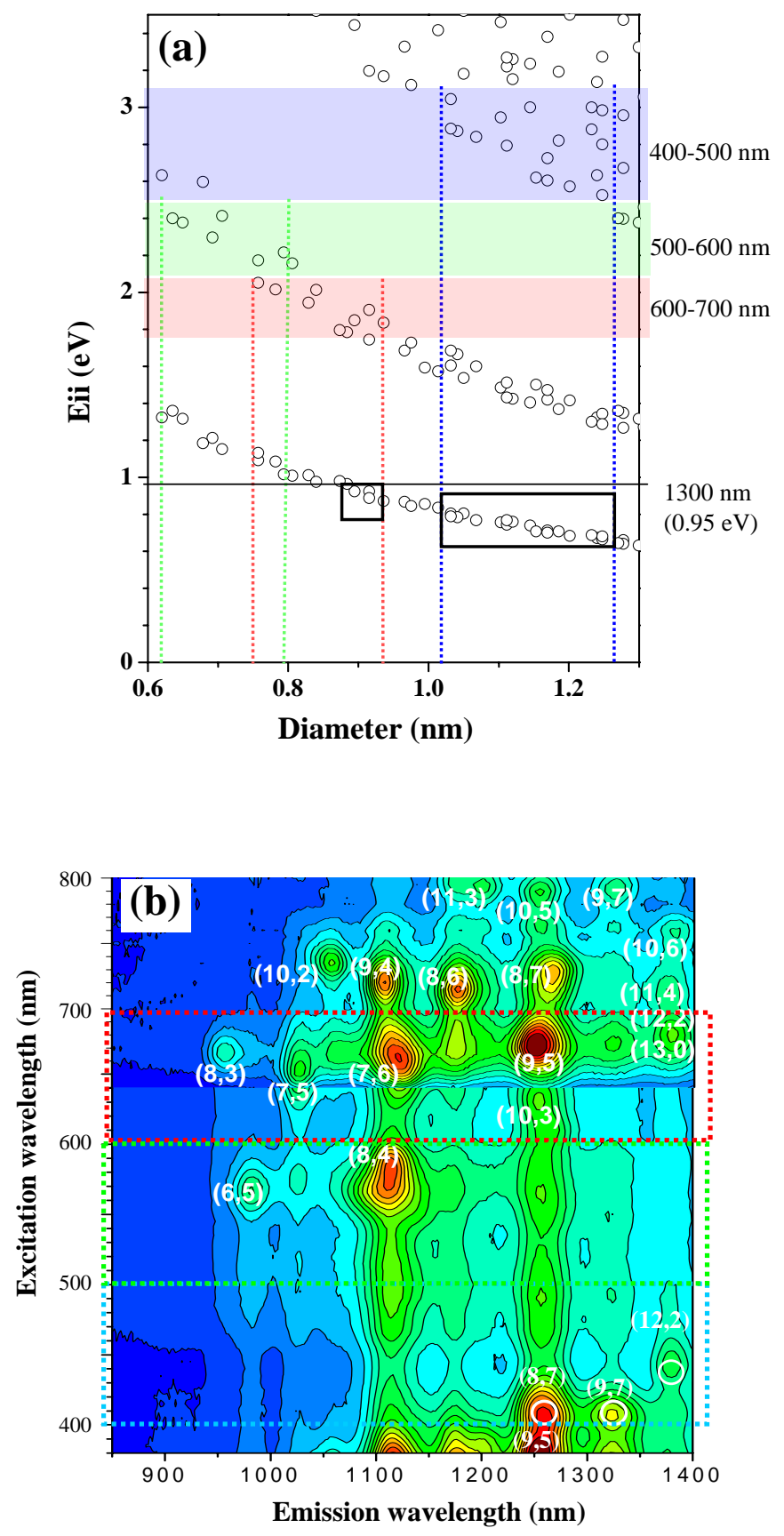
Table 1 The structures of $(m, n)$ SWNTs corresponding to the P1-P12 peaks in Fig. 4

\begin{tabular}{|c|c|c|c|c|}
\hline \multirow[t]{2}{*}{$\begin{array}{c}-\left(I-I_{0}\right) / I_{0} \\
(\%)\end{array}$} & \multicolumn{2}{|c|}{$\begin{array}{c}400-500 \mathrm{~nm} \\
(2.48-3.1 \mathrm{eV})\end{array}$} & \multicolumn{2}{|c|}{$\begin{array}{c}600-700 \mathrm{~nm} \\
(1.77-2.07 \mathrm{eV})\end{array}$} \\
\hline & $(\mathrm{m}, \mathrm{n})$ & $\begin{array}{l}\text { Diameter } \\
\text { (nm) }\end{array}$ & $(m, n)$ & $\begin{array}{c}\text { Diameter } \\
\text { (nm) }\end{array}$ \\
\hline$>80 \%$ & $\begin{array}{l}\text { P7:(6,5), } \\
\text { P8:(7,5), } \\
\text { P1: }(10,2)\end{array}$ & $\begin{array}{l}0.76 \\
0.83 \\
0.88\end{array}$ & P7: $(6,5)$ & 0.76 \\
\hline$>60 \%$ & $\begin{array}{l}\text { P3: }(8,6) \\
\text { P2: }(9,4) \\
\text { P9: }(7,6) \\
\text { P4: }(8,7)\end{array}$ & $\begin{array}{l}0.97 \\
0.91 \\
0.89 \\
1.03\end{array}$ & & \\
\hline$>30 \%$ & $\begin{array}{l}\text { P11: }(9,5) \\
{ }^{*} \text { P5: }(9,7) \\
{ }^{\star} \mathrm{P} 12\end{array}$ & $\begin{array}{l}0.96 \\
\star 1.10\end{array}$ & $\begin{array}{l}\text { P8: }(7,5) \\
\text { P6:(11,4) } \\
\text { P3: }(8,6) \\
\text { P4: }(8,7) \\
\text { P1: }(10,2) \\
\text { *P5: }(9,7)\end{array}$ & $\begin{array}{l}0.83 \\
1.11 \\
0.97 \\
1.03 \\
0.88 \\
1.10\end{array}$ \\
\hline$>10 \%$ & & & $\begin{array}{l}\text { *P12 } \\
\text { P11:(9,5) } \\
\text { P9: }(7,6) \\
\text { *P10 } \\
\text { P2: }(9,4)\end{array}$ & $\begin{array}{l}\star 1.10 \\
0.96 \\
0.90 \\
{ }^{*} 0.97 \\
0.92\end{array}$ \\
\hline
\end{tabular}

*The chiral indexes of P10 and P12 could not be assigned according to the study of Weisman et al.[32]. 